\title{
Repurposing of Linagliptin Similar FDA Approved Drugs as Antidiabetic Agents
}

\author{
Niveditha Nakka ${ }^{1}$, Gouthami Thumma ${ }^{2}$, Swetha Nagilla ${ }^{1}$, Narender Boggula ${ }^{1}$, Vasudha Bakshi ${ }^{1}$, Kiran \\ Gangarapu 1 ,*(D) \\ 1 School of Pharmacy, Anurag Group of Institutions, Venkatapur(V), Ghatakaser (M), Medchal (D), Telangana-501301 \\ 2 University College of Pharmaceutical Sciences, Kakatiya University, Hanamkonda, Warangal, Telangana, India-506 009 \\ * Correspondence: gangakiran1905@gmail.com;
}

Scopus Author ID 37101465100

Received: 6.01.2021; Revised: 15.03.2021; Accepted: 21.03.2021; Published: 8.05.2021

\begin{abstract}
Diabetes mellitus is considered a global epidemic disease and is one of the metabolic diseases affecting individuals irrespective of age, sex, and race. According to WHO epidemiology data, the DM prevalence globally has risen from $4.7 \%$ to $8.5 \%$ from 1980 to 2014. The discovery of new drugs has become more challenging for the pharmaceutical companies even though major investment has made in the conventional drug discovery approach. To overcome this obstacle, drug repurposing is an emerging field of development where an existing drug is tested for treatment. Successful repurposing of zidovudine, minoxidil, sildenafil, celecoxib, aspirin, and topiramate are reported for respective diseases. The present study focused on the computational approach to fetch the favorable drugs from the pool of FDA approved drugs against diabetes. Initially, structure similarity studies were carried out by using the template structure of standard DPP-IV inhibitor, Linagliptin. About 26 drugs have shown similarity, and the other 14 drugs filtered by Pass Online binding energies are determined by molecular docking at the binding site of DPP-IV (PDB ID 2i78). Among these, pranlukast and mirabegron have shown good binding interactions with dock scores of -13.81 and -13.06.
\end{abstract}

Keywords: diabetes mellitus; drug repositioning; linagliptin; molecular docking; SwissSimilarity.

(c) 2021 by the authors. This article is an open-access article distributed under the terms and conditions of the Creative Commons Attribution (CC BY) license (https://creativecommons.org/licenses/by/4.0/).

\section{Introduction}

Diabetes mellitus is defined as a state in which homeostasis of carbohydrate and lipid metabolism is improperly regulated by insulin [1,2]. There are two main categories of this disease - type 1 (insulin-dependent diabetes mellitus, IDDM) and type 2 (non-insulindependent diabetes mellitus, NIDDM) [3]. Type 1 diabetes is typically a juvenile-onset disease and is associated with insulin deficiency, usually resulting from autoimmune destruction of pancreatic beta cells [4]. Type 2 diabetes is typically a disease of adult-onset (although it is becoming increasingly recognized in children) and is caused by a combination of defective insulin secretion with reduced tissues' insulin sensitivity [5]. Hyperglycemia in type 2 diabetic patients can be often managed using a combination of dietary modification and oral hypoglycemic drugs [6]. Type 2 diabetes mellitus (T2DM) accounts for 90 to $95 \%$ of all diabetes cases, increasing incidence [7]. The high risk associated with diabetes leads to a decrease in life expectations. According to WHO, the risk of diabetes is expected to rise by about 511 million by 2030 [8]. In a quest for searching novel targets for type- 2 diabetes, many targets were elucidated, such as Glycogen Synthase Kinase-3, DPP-IV, PPAR- $\gamma, \alpha-$ 
Glucosidase, $\alpha$-amylase, GLP-1, SGLT. One of the best choices is inhibition of the enzyme dipeptidyl peptidase-IV (DPP-IV), which plays an important role in the rapid degradation of the metabolic hormones glucagon-like peptide-1 (GLP-1) and glucose-dependent insulinotropic polypeptide [9,10]. FDA-approved Dipeptidyl-peptidase-IV (DPP-4) inhibitors are sitagliptin, vildagliptin, saxagliptin, linagliptin, and alogliptin [11]. Linagliptin is a novel, orally active, highly specific, and potent inhibitor of DPP-IV that is currently in clinical development to treat T2DM [12].

Drug repurposing (also called drug repositioning, reprofiling, or re-tasking) is a strategy for identifying new uses for approved or investigational drugs outside their original medical indication scope. Successful drug repurposings are: zidovudine used in cancer and repurposed to HIV/AIDS, minoxidil used in hypertension repurposed to hair loss, sildenafil used in angina repurposed to erectile dysfunction; other drugs repurposed are thalidomide, celecoxib, duloxetine, rituximab, raloxifene, dapoxetine, and aspirin [13]. However, it has been observed that drug development efforts for the treatment of diabetes have been largely unsuccessful in the last decade.

In the present study, we here proposed an in silico computational study approach that aims to screen the FDA's approved drugs against diabetes. The human DPP IV structure having PDBID: 2 I78 (https://www.rcsb.org/structure/2I78) was used as a receptor molecule to screen FDA-approved drugs. Linagliptin was used as a standard template to access the similar ligand structures from the approved list of FDA drugs through the SwissSimilarity approach (http://www.swisssimilarity.ch/). The screened hits having similar chemical structures were accessed from FDA and undergoes docking analysis using MOE. The best drugs having efficient binding interactions were further screened for DPP-IV enzyme inhibition studies.

\section{Materials and Methods}

\subsection{Retrieval of protein structure.}

The protein structure of human DPP-IV (PDB ID: 2i78) was accessed from a protein databank. The protein structure was energy minimized using UCSF Chimera 1.10 with an amber force field [14]. Furthermore, VADAR 1.8 online server was used to interpret the protein architecture of helices, beta-sheets, coils, and turns [15]. The Discovery Studio 2.1.0 Client was used to view the 3D structure of target protein and Ramachandran graph generation [16].

\subsection{Repossession of diabetes FDA-approved drugs through SwissSimilarity.}

Linagliptin is commonly known as a DPP-IV inhibitor and is used to treat diabetes as a standard drug.[17] The smile format and chemical structure of linagliptin were retrieved from FDA (https://www.fda.gov/). The SwissSimilarity is an online platform that allows you to identify some chemical hits from FDA and other libraries for your reference structure [18]. Linagliptin was used as a standard template to screen FDA-approved drugs. All the screened drugs were ranked according to their predicted score values. The obtained screened drugs were sketched in ChemSketch and visualized in PyMol [16].

\subsection{Molecular docking.}

Molecular docking was performed on Windows 2010 and all the drugs were retrieved from PubChem database. DPP-IV protein was retrieved from the protein data bank (PDB code: 
2I78), and the enzyme was visualized using the sequence option, and further co-factors were deleted. The partial charge of the protein was adjusted with the help of the force field method AMBER 99. Later, the protein was subjected to 3D protonation at a cut of 12.0, and further hydrogen was added according to standard geometry, and the receptor was energy minimized using force field MMFF94x at $0.01 \mathrm{KJ} /$ mole gradients. The ligand structures were written using a builder module, and adjusting the partial charges using the Hamilton MMFF94 force field method, and subsequently, 3D protonation and hydrogen addition were performed according to standard geometry. Ligands were energy minimized at cut off 12 using force field MMFF94x at a $0.01 \mathrm{KJ} / \mathrm{mole}$ gradient and $6.0 \mathrm{~A}^{\circ}$ grid was generated on the enzyme's active site. Docking was performed using the option simulation followed by the dock on selected active site amino acids using sequence option and eventually docked using setting options such as receptor and solvent, alpha triangle, selected residues, affinity $\mathrm{dG}$, force field refinement, and best 30 poses. After obtaining docking results, the best pose was retained to understand molecular interaction out of 30 given poses for each chemical structure. The resultant best pose score values in the series were used for the analysis of docking and interaction.

\section{Results and Discussion}

\subsection{DPP-IV structural assessment.}

Human DPP-IV is a hydrolase enzyme having four chains and comprises 726 residues. The VADAR 1.8 structure analysis of human DPP-IV depicted that it consists of $16 \%$ (117) $\alpha$ helices, 44\% (325) $\beta$-sheets, 39\% (284) coils, and 20\% (148) turns. The Ramachandran plots and values indicated that $95 \%$ of amino acids existed in the favored region. The Ramachandran graph values showed good accuracy of phi $(\varphi)$ and psi $(\psi)$ angles among the coordinates of the receptor, and most of the residues were plunged in an acceptable region (Figure 1).

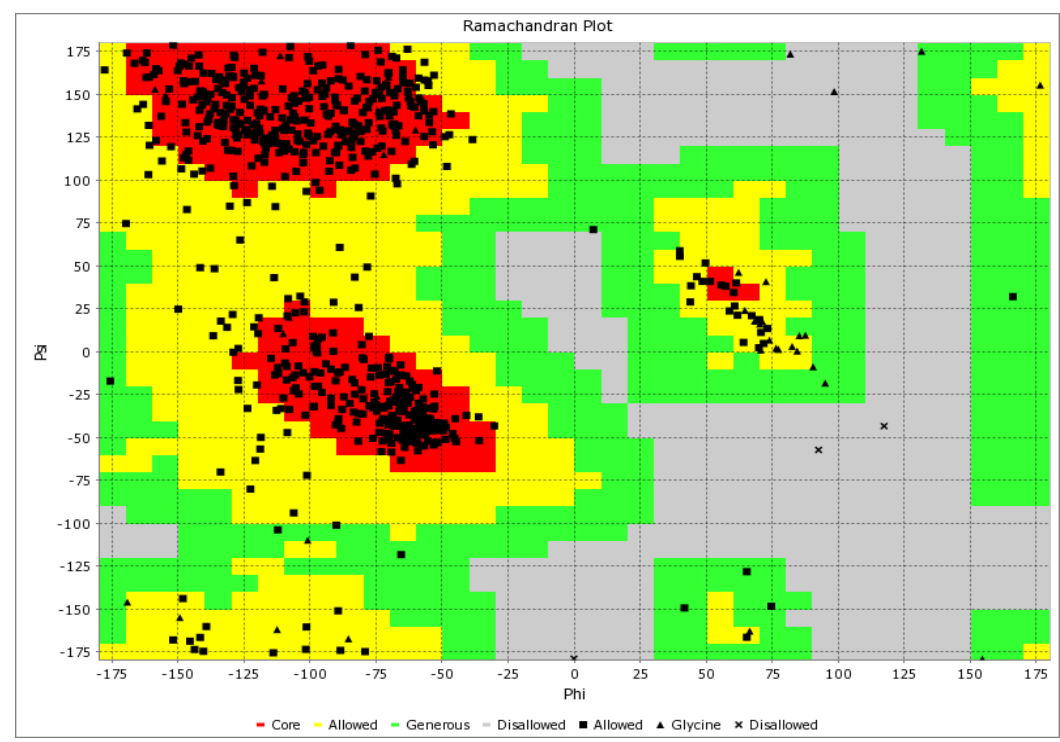

Figure 1. Ramachandran plot of DPP-IV

\subsection{SwissSimilarity study.}

In the drug repositioning approach, the shape-based screening, molecular docking, and drug-genes association are significant parameters for predicting the possible therapeutic effects of known drugs against different targets. Our SwissSimilarity results showed that 14 drugs were selected from 1516 FDA-approved drugs, which showed approximately good structural 
resemblance with the standard drug (Figure 2). The screened drugs were ranked based on similarity scoring values, ranged from $0-1$. The 0 value represents dissimilarity between compounds whereas, 1 is used for highly identical compounds in the screening approach. Our results show that all screen drugs' scoring values range from 0.006-0.184, as tabulated in Table 1. Although SwissSimilarity scoring values were low relative to the reference standard value range, a detailed docking study was run against all screened 36 drugs to check their binding interactions behavior compared with donepezil. Based on these docking results, drugs Figure 2 were selected for further analysis.

\subsection{Screened drugs and their possible involvement in different diseases.}

On the score value of SwissSimilarity, 14 drugs Pranlukast, Mirabegron, Aripiprazole, Dofetilide, Apixaban, Bevantolol, Fingolimod, Verapamil, Dipivefrin, Nicardipine, Bimatoprost, and Simvastatin were selected and evaluated for binding pattern analysis against DPP-IV. It was observed that all drugs showed good binding interaction within the active region of the target enzyme. Before going to further analysis, we discuss prior studies to check the functional features and their involvement in different diseases. Pranlukast is a benzopyran derivative and cysteinyl leukotriene receptor-1 antagonist and acts against tuberculosis, particularly on Mycobacterium tuberculosis ArgJ [19]. Mirabegron is a carboxylic acid amide drug, a selective adrenoceptor agonist, and acts as adipose tissue activation and bile acids' metabolism [20]. Aripiprazole is a piperazine derivative and antipsychotic drug repurposed as an inhibitor of sterol biosynthesis in Candida albicans [21]. Apixaban chemically pyrazolo[3,4c] pyridine analog and used in blood clotting agent by inhibiting factor Xa [22]. Bevantolol is an $\beta 1$-adrenoceptor antagonist and repurposed to Huntington's chorea [23].

Table 1. SwissSimilarity and Lipinski rule of five values of FDA-approved drugs.

\begin{tabular}{|c|c|c|c|c|c|c|c|c|}
\hline S.no & Drug & M.Wt & BA & BD & ogP & TPSA & MolVol & D. L Score \\
\hline 1 & Linagliptin & 472 & 6 & 2 & 1.89 & 85.4 & 496 & 1.07 \\
\hline 2 & Carbetocin & 987 & 13 & 13 & -2.62 & 302 & 1019 & -0.3 \\
\hline 3 & Telaprevir & 679 & 8 & 4 & 2.4 & 146 & 742 & 0.78 \\
\hline 4 & Pranlukast & 481 & 7 & 2 & 5.8 & 101 & 469 & 0.95 \\
\hline 5 & Felypressin & 1038 & 15 & 16 & -4.9 & 324 & 1021 & 0.06 \\
\hline 6 & Mirabegron & 396 & 5 & 5 & 2.5 & 82 & 369 & 1.71 \\
\hline 7 & Verapamil & 454 & 6 & 0 & 5.28 & 51.6 & 514 & 1.01 \\
\hline 8 & Ximelagatran & 473 & 7 & 5 & 0.89 & 122 & 493 & 1.05 \\
\hline 9 & Ibutilide & 384 & 4 & 2 & 4 & 61.9 & 396 & 0.85 \\
\hline 10 & Amprenavir & 505 & 7 & 4 & 3.24 & 109 & 470 & 1.17 \\
\hline 11 & Remikiren & 630 & 7 & 5 & 2.8 & 130 & 644 & -0.26 \\
\hline 12 & Iloprost & 360 & 4 & 3 & 3.6 & 61.2 & 416 & 0.84 \\
\hline 13 & Simvastatin & 418 & 5 & 1 & 4.2 & 56.7 & 490 & 0.98 \\
\hline 14 & Pimecrolimus & 809 & 11 & 2 & 5.6 & 126 & 866 & 0.6 \\
\hline 15 & Rescinnamine & 634 & 10 & 1 & 3.9 & 91 & 661 & 1.09 \\
\hline 16 & Darunavir & 547 & 8 & 4 & 3.4 & 118 & 503 & 0.5 \\
\hline 17 & Alfacalcidol & 400 & 2 & 2 & 7.4 & 31 & 506 & 0.4 \\
\hline 18 & Aripiprazole & 447 & 3 & 1 & 4.9 & 39 & 431 & 1.35 \\
\hline 19 & Apixaban & 459 & 5 & 2 & 2 & 88 & 475 & 0.2 \\
\hline 20 & Alfuzosin & 389 & 6 & 3 & 2 & 89 & 384 & 1.08 \\
\hline 21 & Cisatracurium Besylate & 1242 & 18 & 0 & 8 & 185 & 1201 & 0.6 \\
\hline 22 & Bevantolol & 345 & 5 & 2 & 3.1 & 51 & 355 & 0.9 \\
\hline 23 & Nicardipine & 479 & 7 & 1 & 3.7 & 89 & 502 & 1.6 \\
\hline 24 & Dipivefrin & 351 & 6 & 2 & 2.3 & 69 & 395 & 1.7 \\
\hline 25 & Dofetilide & 441 & 6 & 2 & 1.8 & 95 & 397 & 1 \\
\hline 26 & Azilsartan Medoxomil & 568 & 10 & 1 & 3.7 & 117 & 557 & 0.8 \\
\hline
\end{tabular}


<smiles>O=C(Nc1ccc2c(=O)cc(-c3nnn[nH]3)oc2c1)c1ccc(OCCCCc2ccccc2)cc1</smiles>

1. Pranlukast<smiles>Cc1ccc(C(=O)Cc2ccc(CCCC(C)c3ccccc3)cc2)nc1</smiles>

2. Mirabegron<smiles>O=C1CCc2ccc(OCCCCC3CCC(c4cccc(Cl)c4Cl)CC3)cc2N1</smiles>

3. Aripiprazole<smiles>COc1ccc(-n2nc(C(N)=O)c3c2C(=O)N(c2ccc(N4CCCCC4=O)cc2)CC3)cc1</smiles>

4. Apixaban<smiles>Cc1nc(N(C)CCCNC(=O)C2CCCO2)nc2cc3c(cc12)OCO3</smiles>

5. Alfuzosin<smiles>[CH]C(CNCCc1ccc(OC)c(OI)c1)COc1cccc([18F])c1</smiles>

6. Bevantolol<smiles>CCCC(C)(CCCC(C)CCc1ccc(CC)c(CC)c1)C(C)(C)C</smiles>

7. Verapamil

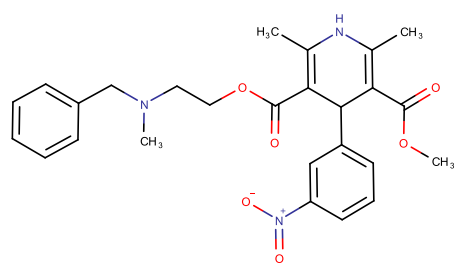

8. Nicardipine<smiles>CNCC(C)c1ccc(OC(=O)C(C)(C)C)c(OC(=O)C(C)(C)C)c1</smiles><smiles>O=C(O)Nc1ccc(OCCP(O)CCc2ccc(NS(=O)(=O)O)cc2)cc1</smiles>

10. Dofetilide<smiles>CCCC(=O)CCC/C=C\C[C@@H]1[C@@H](/C=C/C[C@H](C)CCc2ccccc2)[C@H](C)C[C@H]1C</smiles>

9. Dipivefrin

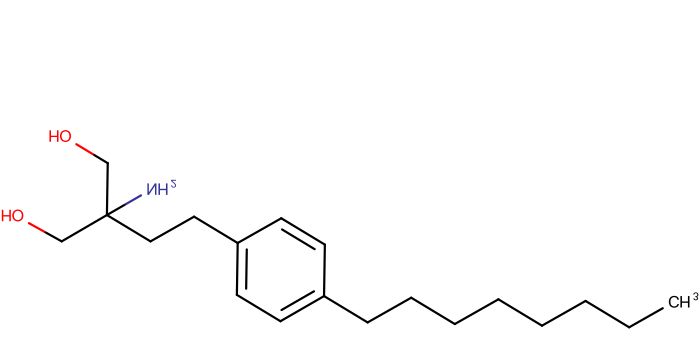

13. Fingolimod<smiles>CCCCCCCC(CO)CCCC(C)c1ccc(C(C)(C)C(C)(C)C)cc1</smiles>

12. Ibutilide<smiles>C[C@@H]1CC(=O)O[C@H](CC[C@H]2[C@@H](C)C=CC3=C[C@H](C)C[C@@H](CC(=O)C(C)(C)CO)[C@@H]32)C1</smiles>

14. Simvastatin

Figure 2. 2D structures of Selected drugs.

The drugs and their indications in disease are specified in Table 2.

Table 2. Role of Selected drugs in diseases.

\begin{tabular}{l|l|l} 
S.No & Drug \\
\hline 1 & Pranlukast
\end{tabular}




\begin{tabular}{l|l|l|l}
\hline S.No & Drug & Function & Disease \\
\hline 2 & Dipivefrin & $\begin{array}{l}\text { Mediated by a1,a2 adrenoreceptors (reduces eye } \\
\text { pressure) } \\
\text { b2 mediated action (increases conductivity of } \\
\text { trabecular cells) }\end{array}$ & Glaucoma \\
\hline 3 & Mirabegron & Activation of Beta-3 Receptors & Overactive bladder \\
\hline 4 & Aripiprazole & $\begin{array}{l}\text { Partial agonist of Dopamine D2, serotonin 5HT1A } \\
\text { Antagonist of serotonin 5HT2A }\end{array}$ & Schizophrenia \\
\hline 5 & Bimatoprost & Stimulates prostamide receptors & High ocular pressure \\
\hline 6 & Fingolimod & Induces S1P1 down-regulation & $\begin{array}{l}\text { Immunosuppressant } \\
\text { Sclerosis) }\end{array}$ \\
\hline 7 & Apixaban & Reversible direct inhibitor of clot-bound factor Xa. & Vein Thrombosis \\
\hline 8 & Bevantolol & Beta-1 adrenoceptor antagonist & Calcium channel blocker \\
\hline 9 & Alfuzosin & $\alpha_{1}$ adrenergic receptor antagonist & Benign prostatic hyperplasia \\
\hline 10 & Verapamil & Inhibits voltage-dependent calcium channels & Calcium channel blocker \\
\hline 11 & Nicardipine & Calcium ion antagonist & Calcium channel blockers \\
\hline 12 & Ibutilide & Blocks delayed rectifier potassium current & Antiarrhythmic agents (Class II) \\
\hline 13 & Dofetilide & Selectively blocks outward potassium current & Antiarrhythmic agents (Class III) \\
\hline 14 & Simvastatin & HMG-CoA reductase inhibitor & Hypolipidemic agents
\end{tabular}

\subsection{Molecular docking.}

A molecular docking experiment is the best approach to study the binding conformation of ligands within the active region of target proteins. To evaluate the best drug, all the screened drugs were docked against DPP-IV separately, and complexes were analyzed based on the lowest binding energy values (dock score). Results of the docking score are enlisted in Table 3 and Figure 3. Pranlukast showed the lowest dock score (-13.81) compared to all other screened drugs. Similarly, Mirabegron, Aripiprazole, Dofetilide, and Apixaban, also displayed good docking score values $(-13.06,-13.61,-13.46,-12.91)$, respectively. Bevantolol and Fingolimod both exhibited-12.7 while other drugs such as Verapamil, Dipivefrin, Nicardipine, Bimatoprost, and Simvastatin have docking scores of -12.01, -11.27, -10.49, -11.56, and 11.53. To better compare our docking results, linagliptin was docked against DPP-IV having the same parameters and observed it possessed -11.48. Based on docking energy value results, ten drugs (Pranlukast, Mirabegron, Aripiprazole, Dofetilide, Apixaban, Bevantolol, Fingolimod, Verapamil, Dipivefrin, Nicardipine, Bimatoprost, and Simvastatin) showed comparable results with linagliptin docking energy value and selected for further analysis.

Table 3. Molecular docking score and interactions of FDA approved drugs.

\begin{tabular}{|c|c|c|c|c|}
\hline S.No & Drug & Dock Score & Receptor & Distance \\
\hline 01 & Pranlukast & -13.81 & $\begin{array}{l}\text { CYS551 (2.61); } \\
\text { ARG356(3.00) }\end{array}$ & $\begin{array}{l}\text { H-donor } \\
\text { H-acceptor }\end{array}$ \\
\hline 02 & Mirabegron & -13.06 & $\begin{array}{l}\text { SER209(2.88) } \\
\text { PRO359(4.03) } \\
\text { TYR662(3.96) }\end{array}$ & $\begin{array}{l}\text { H-donor } \\
\text { H-donor } \\
\text { pi-pi }\end{array}$ \\
\hline 03 & Aripiprazole & -13.61 & $\begin{array}{l}\text { GLU206 (2.72) } \\
\text { ILE405(2.80) }\end{array}$ & $\begin{array}{l}\text { H-donor } \\
\text { H-donor }\end{array}$ \\
\hline 04 & Apixaban & -12.91 & TYR 666 (3.52) & pi-pi \\
\hline 05 & Alfuzosin & -12.47 & ARG669 (2.14), PHE357(1.89) & $\begin{array}{l}\text { H-donor } \\
\text { H-acceptor }\end{array}$ \\
\hline 06 & Bevantolol & -12.73 & TYR 547 (3.04) & H-acceptor \\
\hline 07 & Verapamil & -12.01 & PHE $357(3.85)$ & H-pi \\
\hline 08 & Nicardipine & -10.49 & $\begin{array}{l}\text { GLU } 205(2.47) \\
\text { GLU } 206(3.00)\end{array}$ & $\begin{array}{l}\text { H-donor } \\
\text { H-donor }\end{array}$ \\
\hline 09 & Dipivefrin & -11.27 & $\begin{array}{l}\text { SER } 630(2.69) \\
\text { HIS } 126(3.40)\end{array}$ & $\begin{array}{l}\text { H-donor } \\
\text { H-acceptor }\end{array}$ \\
\hline
\end{tabular}




\begin{tabular}{|c|c|c|c|c|}
\hline S.No & Drug & Dock Score & Receptor & Distance \\
\hline & & & $\begin{array}{l}\text { GLU } 206(2.46) \\
\text { ARG } 669(3.02)\end{array}$ & $\begin{array}{l}\text { H-acceptor } \\
\text { H-acceptor }\end{array}$ \\
\hline 10 & Dofetilide & -13.46 & $\begin{array}{l}\text { ILE } 405(2.88) \\
\text { ARG125(3.49) }\end{array}$ & $\begin{array}{l}\text { H-donor } \\
\text { H-acceptor }\end{array}$ \\
\hline 11 & Bimatoprost & -11.56 & $\begin{array}{l}\text { TYR } 666(2.29) \\
\text { SER 552(4.67) }\end{array}$ & $\begin{array}{l}\mathrm{H} \text {-acceptor } \\
\mathrm{Pi}-\mathrm{H}\end{array}$ \\
\hline 12 & Ibutilide & -12.31 & $\begin{array}{l}\text { GLU } 206(2.78) \\
\text { TYR } 666(3.51)\end{array}$ & $\begin{array}{l}\text { H-donor } \\
\text { Pi-pi }\end{array}$ \\
\hline 13 & Fingolimod & -12.74 & $\begin{array}{l}\text { SER 630(2.54) } \\
\text { TYR 666(4.55) }\end{array}$ & $\begin{array}{l}\text { H-donor } \\
\text { H-pi }\end{array}$ \\
\hline 14 & Simvastatin & -11.53 & SER 630(2.62) & H-acceptor \\
\hline
\end{tabular}

\subsection{Docking binding analysis}

3.5.1. Pranlukast and Dipivefrin binding analysis.

The Pranlukast binds with DPP-IV in good conformational position inside active regions compassed by and $\mathrm{H}$-bond interactions with Cys551 and Arg356 residues with a bond distance of 2.61 and 3.00, respectively. The tetrazole group in pranlukast forms pi-pi interactions with Phe357. Similarly, dipivefrin binds with DPP-IV and shown a couple of Hbond interactions with different amino acids Ser630, His126, Glu206, and Arg669 with a bond distance of 2.69, 3.40, 2.46, and 3.02 with docking scores of -13.81 and -11.27 , respectively.

\subsubsection{Mirabegron and Aripiprazole binding analysis.}

Mirabegron binds with DPP-IV in good conformational position inside active regions compassed by and H-bond interactions with Ser209, Pro359, and Tyr662 residues with a bond distance of 2.88, 4.03, and 3.96 respectively and aripiprazole showing conformational position inside the active region and H-bond interactions with Glu206, Ile405 residues with a bond distance of 2.72 and 2.80 and the docking scores are -13.06 and -13.6 respectively.

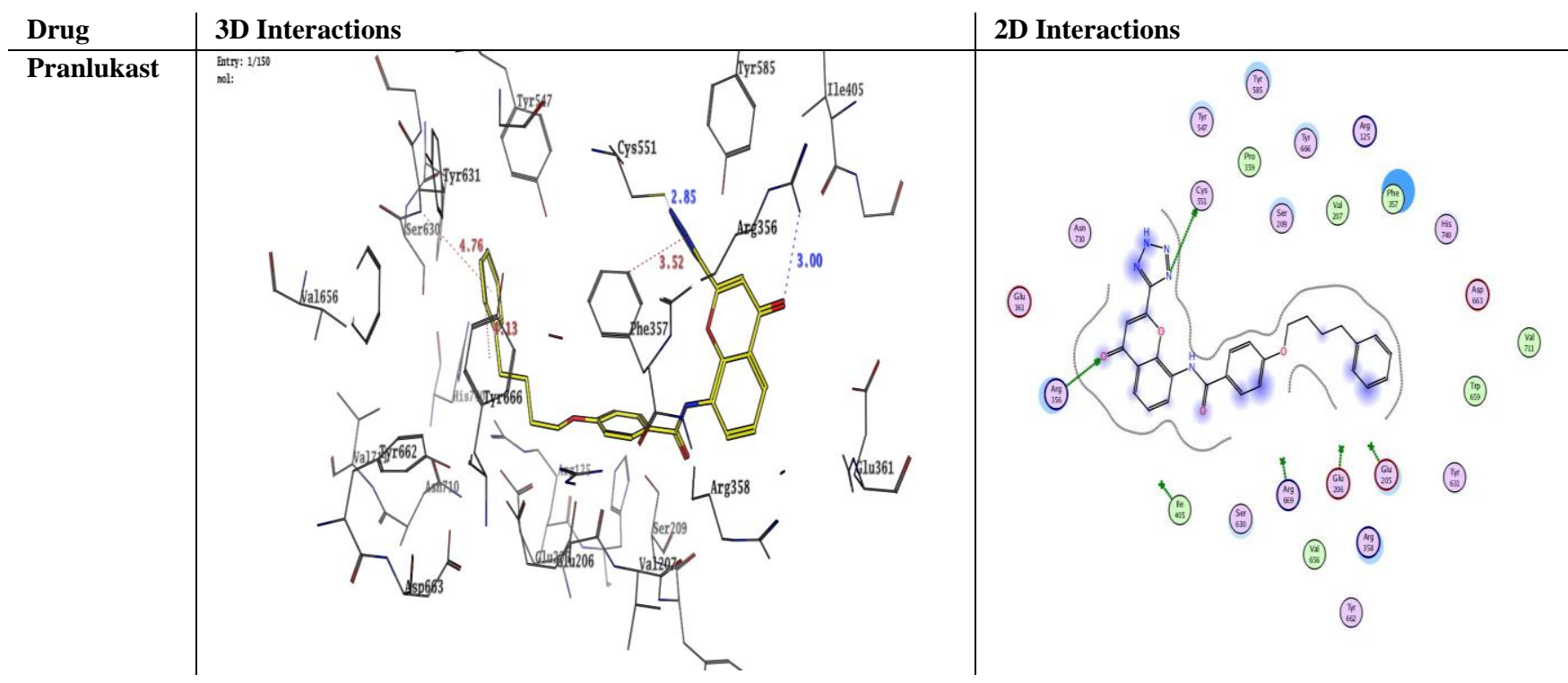




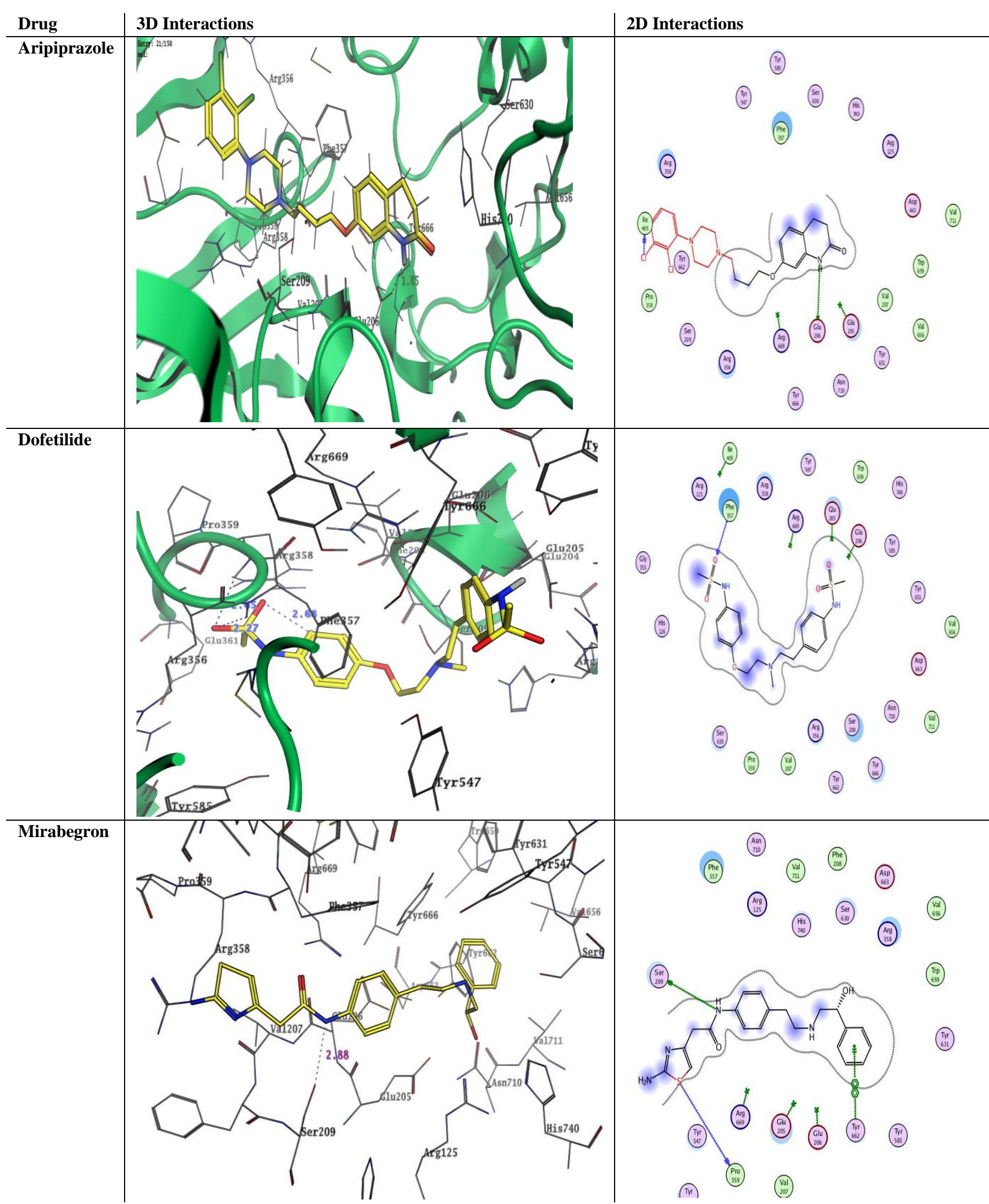

Figure 3. 3D and 2D interactions of Drugs against DPP-IV target (PDB ID 2i78).

\subsubsection{Bimatoprost and Fingolimod binding analysis.}

Bimatoprost and Fingolimod's docked complexes were examined based on interaction behavior within active binding site residues of DPP-IV. Bimatoprost and Fingolimod bind with DPP-IV in a good conformational position inside the active region. In both docking molecules, two bonds were observed against Tyr666, Ser552, and Tyr666, Ser630, respectively, with a bond distance of 2.29, 4.67, and 4.55, 2.54, and the docking scores are $-11.56,-12.74$. 
3.5.4. Biding analysis of Apixaban and Bevantolol.

Apixaban and Bevantolol docked complexes were examined to interpret the binding conformations pattern within the active region of DPP-IV. In both compounds docking, single interaction was observed against Tyr 666, and Tyr547 with a bond distance of 3.52 and 3.04 and the docking scores are $-12.91,-12.73$, respectively.

\subsubsection{Binding analysis of Alfuzosin and Verapamil.}

The docked complexes of both Alfuzosin and Verapamil were examined based on interaction behavior within active binding site residues of DPP-IV. Both bind with DPP-IV in a good conformational position inside the active region. In Alfuzosin docking, two bonds were observed against Arg669, Phe357 with a bond distance of 2.14, 1.89, whereas verapamil formed H-bond against Phe 357 with a bond distance of 3.85 and docking scores are -12.47 and -12.01 , respectively.

\subsubsection{Binding analysis of Nicardipine and Ibutilide.}

Nicardipine and Ibutilide docked complexes were examined to interpret the binding conformations pattern within the active region of DPP-IV. In Nicardipine docking, two interactions were observed against Glu205 and Glu206 with a bond distance of 2.47, 3.00 and Ibutilide has interacted with two amino acids Glu206, Tyr666 with a bond distance of 2.78, 3.51 and the docking scores are $-10.49,-12.31$ respectively.

\subsubsection{Dofetilide and Simvastatin binding analysis.}

The docked complexes of both Dofetilide and Simvastatin were examined based on interaction behavior within active binding site residues of DPP-IV. Both bind with DPP-IV in a good conformational position inside the active region. In Dofetilide docking, two bonds were observed against Arg125, Ile405 with a bond distance of 3.49, 2.88, whereas Simvastatin formed H-bond against Ser630 with a bond distance of 2.62 and docking scores are -13.46 and -11.53 , respectively.

\section{Conclusions}

The present work is focused on in silico computational studies to find new leads by structure similarity approach for antidiabetic agents. The structure similarity studies were carried out using the template structure of DPP IV inhibitor, Linagliptin, from the pool of FDAapproved drugs. SwissSimilarity results showed that 14 drugs were selected from 1516 FDAapproved drugs, which showed approximately good structural resemblance with standard drugs. The drugs which have shown potent binding interactions were determined by molecular docking studies against DPP-IV (PDB ID 2I78). From the binding interactions, we found that Pranlukast and Mirabegron have shown good binding interactions with a docking score of 13.81 and -13.06, respectively, against DPP-IV. In the future, these drugs will be studied further for detail mechanistic studies for the repurposing approach for the development of an antidiabetic drug.

\section{Funding}

This research received no external funding. 


\section{Acknowledgments}

The authors are thankful to Management for providing the necessary support for the research work.

\section{Conflicts of Interest}

The authors declare no conflict of interest.

\section{References}

1. Belder, R.; Johnston, P.; Lawson, F.; Ping, L.; Xiaodan, W.E.I. Treatment of type 2 diabetes mellitus patients. Google Patents: 2018. Available online: https://patents.google.com/patent/US20160296601A1/en.

2. Maqbool, M.; Dar, M.A.; Gani, I.; Mir, S.A. Animal models in diabetes mellitus: an overview. Journal of Drug Delivery and Therapeutics 2019, 9, 472-475, https://doi.org/10.22270/jddt.v9i1-s.2351.

3. Bellamy, L.; Casas, J.-P.; Hingorani, A.D.; Williams, D. Type 2 diabetes mellitus after gestational diabetes: a systematic review and meta-analysis. The Lancet 2009, 373, 1773-1779, https://doi.org/10.1016/S01406736(09)60731-5.

4. Canivell, S.; Gomis, R. Diagnosis and classification of autoimmune diabetes mellitus. Autoimmun. Rev. 2014, 13, 403-407, https://doi.org/10.1016/j.autrev.2014.01.020.

5. Pirot, P.; Cardozo, A.K.; Eizirik, D.L. Mediators and mechanisms of pancreatic beta-cell death in type 1 diabetes. Arquivos Brasileiros de Endocrinologia \& Metabologia 2008, 52, 156-165, https://doi.org/10.1590/S0004-27302008000200003.

6. Inzucchi, S.E.; Bergenstal, R.M.; Buse, J.B.; Diamant, M.; Ferrannini, E.; Nauck, M.; Peters, A.L.; Tsapas, A.; Wender, R.; Matthews, D.R. Management of hyperglycemia in type 2 diabetes: a patient-centered approach: position statement of the American Diabetes Association (ADA) and the European Association for the Study of Diabetes (EASD). Diabetes Spectr. 2012, 25, 154-171. Avavilable online: https://care.diabetesjournals.org/content/35/6/1364.full-text.pdf.

7. Chen, L.; Magliano, D.J.; Zimmet, P.Z. The worldwide epidemiology of type 2 diabetes mellitus-present and future perspectives. Nature Reviews Endocrinology 2012, 8, 228-236, https://doi.org/10.1038/nrendo.2011.183.

8. Shaw, J.E.; Sicree, R.A.; Zimmet, P.Z. Global estimates of the prevalence of diabetes for 2010 and 2030. Diabetes Res. Clin. Pract. 2010, 87, 4-14, https://doi.org/10.1016/j.diabres.2009.10.007.

9. Holst, J.J.; Deacon, C.F.; Vilsbøll, T.; Krarup, T.; Madsbad, S. Glucagon-like peptide-1, glucose homeostasis and diabetes. Trends Mol. Med. 2008, 14, 161-168, https://doi.org/10.1016/j.molmed.2008.01.003.

10. Matteucci, E.; Giampietro, O. Dipeptidyl Peptidase-4 (CD26): Knowing the Function before Inhibiting the Enzyme. Curr. Med. Chem. 2009, 16, 2943-2951, https://doi.org/10.2174/092986709788803114.

11. Gallwitz, B. Sitagliptin: profile of a novel DPP-4 inhibitor for the treatment of type 2 diabetes. Drugs Today 2007, 43, 13-25, https://doi.org/10.1358/dot.2007.43.1.1043909.

12. Blech, S.; Ludwig-Schwellinger, E.; Gräfe-Mody, E.U.; Withopf, B.; Wagner, K. The Metabolism and Disposition of the Oral Dipeptidyl Peptidase-4 Inhibitor, Linagliptin, in Humans. Drug Metab. Disposition 2010, 38, 667, https://doi.org/10.1124/dmd.109.031476.

13. Pushpakom, S.; Iorio, F.; Eyers, P.A.; Escott, K.J.; Hopper, S.; Wells, A.; Doig, A.; Guilliams, T.; Latimer, J.; McNamee, C.; Norris, A.; Sanseau, P.; Cavalla, D.; Pirmohamed, M. Drug repurposing: progress, challenges and recommendations. Nature Reviews Drug Discovery 2019, 18, 41-58, https://doi.org/10.1038/nrd.2018.168.

14. Chimera User's Guide. Available online: http://www.cgl.ucsf.edu/chimera/pdf/UsersGuide1.10.pdf

15. Willard, L.; Ranjan, A.; Zhang, H.; Monzavi, H.; Boyko, R.F.; Sykes, B.D.; Wishart, D.S. VADAR: a web server for quantitative evaluation of protein structure quality. Nucleic Acids Res. 2003, 31, 3316-3319, https://doi.org/10.1093/nar/gkg565.

16. Hassan, M.; Raza, H.; Abbasi, M.A.; Moustafa, A.A.; Seo, S.-Y. The exploration of novel Alzheimer's therapeutic agents from the pool of FDA approved medicines using drug repositioning, enzyme inhibition and kinetic mechanism approaches. Biomed. Pharmacother. 2019, 109, 2513-2526, https://doi.org/10.1016/j.biopha.2018.11.115. 
17. Makrilakis, K. The Role of DPP-4 Inhibitors in the Treatment Algorithm of Type 2 Diabetes Mellitus: When to Select, What to Expect. Int. J. Env. Res. Public Health 2019, 16, https://doi.org/10.3390/ijerph16152720.

18. Zoete, V.; Daina, A.; Bovigny, C.; Michielin, O. SwissSimilarity: A Web Tool for Low to Ultra High Throughput Ligand-Based Virtual Screening. J. Chem. Inf. Model. 2016, 56, 1399-1404, https://doi.org/10.1021/acs.jcim.6b00174.

19. Mishra, A.; Mamidi, A.S.; Rajmani, R.S.; Ray, A.; Roy, R.; Surolia, A. An allosteric inhibitor of Mycobacterium tuberculosis ArgJ: Implications to a novel combinatorial therapy. EMBO Mol. Med. 2018, 10, e8038, https://doi.org/10.15252/emmm.201708038.

20. Baskin, A.S.; Linderman, J.D.; Brychta, R.J.; McGehee, S.; Anflick-Chames, E.; Cero, C.; Johnson, J.W.; O’Mara, A.E.; Fletcher, L.A.; Leitner, B.P.; Duckworth, C.J.; Huang, S.; Cai, H.; Garraffo, H.M.; Millo, C.M.; Dieckmann, W.; Tolstikov, V.; Chen, E.Y.; Gao, F.; Narain, N.R.; Kiebish, M.A.; Walter, P.J.; Herscovitch, P.; Chen, K.Y.; Cypess, A.M. Regulation of Human Adipose Tissue Activation, Gallbladder Size, and Bile Acid Metabolism by a $\beta 3$-Adrenergic Receptor Agonist. Diabetes 2018, 67, 2113, https://doi.org/10.2337/db18-0462.

21. Rajasekharan, S.K.; Lee, J.-H.; Lee, J. Aripiprazole repurposed as an inhibitor of biofilm formation and sterol biosynthesis in multidrug-resistant Candida albicans. Int. J. Antimicrob. Agents 2019, 54, 518-523, https://doi.org/10.1016/j.ijantimicag.2019.05.016.

22. Wong, P.C.; Pinto, D.J.P.; Zhang, D. Preclinical discovery of apixaban, a direct and orally bioavailable factor Xa inhibitor. J. Thromb. Thrombolysis 2011, 31, 478-492, https://doi.org/10.1007/s11239-011-0551-3.

23. Bashir, H. Emerging therapies in Huntington's disease. Expert Rev. Neurother. 2019, 19, 983-995, https://doi.org/10.1080/14737175.2019.1631161. 